\title{
ABORDAGENS PARA UM ENSINO DE HISTÓRIA HUMANIZADO
}

\author{
Ana Paula dos Santos Lima (UL)*
}

\section{RESUMO}

A argumentação que se segue é uma revisão bibliográfica que tem por objetivo identificar abordagens que contribuam para a efetivação de práticas pedagógicas humanizadas para o ensino de História. São sugeridas três abordagens nesse sentido: o local, o quotidiano e a verdade. A história local como uma forma de compreender a consciência histórica das experiências individuais e/ou coletivas. A inserção do quotidiano demonstrando que a história é uma estrutura em progresso e construída pelos homens no tempo. E a reflexão sobre o conceito de verdade que permite perceber a dinâmica inerente à interpretação dos factos históricos.

Palavras chave: Ensino - História - Humanizado.

\section{ABSTRACT}

\section{APPROACHES TO HUMANIZED HISTORY TEACHING}

The following argument is an bibliographical review that aims to identify approaches that contributes to the accomplishment of humanized pedagogical practices for the teaching of History. Initially three approaches are suggested in this sense: the local, the everyday and the truth. Local history as a way of understanding the historical awareness of individual and/or collective experiences. The insertion of daily life demonstrates that history is a structure in progress and built by men in time, as well as the reflection of the concept of truth that allows one to perceive the dynamics inherent to the interpretation of historical facts.

Keywords: Education - History - Humanized.

\section{RESUMEN}

\section{ABORDAJES PARA UNA ENSEÑANZA DE HISTORIA HUMANIZADA}

La argumentación que se sigue es una revisión bibliográfica que tiene como objetivo identificar abordajes que contribuyan para hacer efectivas las prácticas pedagógicas humanizadas para la enseñanza de Historia. Son sugeridas tres abordajes en es sentido: el local, el cuotidiano y la verdad. La historia local como una forma de comprender la conciencia histórica de las experien-

* Licenciada em História. Doutora em Ensino, Filosofia e História das Ciências. Investigadora colaboradora no Centro de História da Faculdade de Letras - Universidade de Lisboa. 
cias individuales y/o colectivas. La inserción del cuotidiano demostrando que la historia es una estructura en progreso y construida por los hombres en el tiempo. Y la reflexión sobre el concepto de verdad que permite percibir la dinámica inherente a la interpretación de los hechos históricos.

Palabras clave: Enseñanza - Historia - Humanizada.

\section{CONSIDERAÇÕES INICIAIS}

Passámos pela era dos extremos, viajámos no "loop" da montanha russa e continuamos em plena velocidade rumo ao bem viver social. Expressões relacionadas com terrorismo, populismos, questões políticas e sociais referentes à imigração atravessam o nosso quotidiano.

As redes sociais criaram uma nova ordem de comunicação e convívio onde cada vez mais a aparência se reveste de instâncias de poder com grande teor de alienação e servidão. As "selfies" dominam as experiências quotidianas com um ideal narcisista. Parece que a juventude "coca-cola" vai dando lugar ao jovem "myself". Na escola esses dilemas aparecem em sua maior expressão e demonstram os desafios do nosso tempo. São os resultados espetaculares e aterrorizantes da "globalização negativa" que ameaça as condições de vida em todo o mundo.

A nossa realidade vai sendo gerada com os fios das experiências dos integrantes de uma geração que se reconhece nas ações e confissões da recente onda de "reality shows". Os fãs e viciados desses programas consistem, em grande parte, na substantiva maioria dos nossos contemporâneos, sendo que a competição fútil, a ditadura estética e as relações artificiais são, provavelmente, a própria composição do ser.

Desta forma, "integrar", talvez seja desde sempre a palavra de ordem, logo seguida por "respeitar", na construção de uma cidadania plena, com liberdades, oportunidades e equidade. "Formar" é outro importante desafio em contraposição ao mero infor- mar, e claro, "amar", sentimento desnudado de objetividade, mas que é a mais plena expressão da escola humanizada.

0 ensino de história pressupõe expor diversidades culturais, religiosas, sociais e económicas através de debates e problematizações que valorizem um olhar local, as ações do quotidiano e o exercício da crítica. É assim que ao educar se intervém efetivamente e responsavelmente no mundo unindo saberes com práticas.

Enquanto mediador no processo de ensino e de aprendizagem o professor deve ajudar no desenvolvimento da autonomia dos alunos, no seu processo de personalização, bem como, ajudá-los a criar dúvidas e mesmo com elas conviver, assim realizando sempre uma reflexão sobre a prática pedagógica.

\section{LOCAL}

$\mathrm{Na}$ atualidade, enquanto o mundo passa por profundas transformações e rápidos avanços no sentido económico, social, político e tecnológico, a escola tem o desafio de acompanhar esse permanente processo de mutação. Assim, pensa-se numa educação dinâmica, humanística e formativa que prepare o indivíduo da melhor maneira possível para enfrentar a problemática do quotidiano. Conforme assinala Monteiro (2004) as teorias e os conceitos orientadores das práticas educativas não têm que durar para sempre, por isso, a escola humanizada deve ser vista como um espaço de cultura que tem por obrigação permitir, promover e dinami- 
zar, a expressão e formação cultural do jovem e favorecer o processo de socialização, bem como promover o processo de personalização. Sendo assim indispensável uma ação educativa inter e multidisciplinar, onde seja relevante a participação, a crítica social dos conteúdos, atividades que propiciem a formação da cidadania, de um conhecimento prudente para uma vida decente.

A escola humanizada não permite que as desigualdades sociais e económicas sejam fatores de exclusão escolar e procura assegurar a diversidade étnica, social e cultural dos alunos ao promover a igualdade de oportunidades, criando assim um ambiente de ensino plural (MONTEIRO, 2004). Para tal, espera-se que o professor reflita sobre sua prática pedagógica de forma a sentir os desafios do tempo presente e intervenha de uma maneira crítica na construção de um ensino que valorize as questões humanas e sociais. Equivalendo salientar que a educação inter e multicultural demonstra ser de crucial importância numa Europa mergulhada em questões relativas à imigração, muitas vezes mal reguladas e não integradoras. Perante esta conjuntura é mister refletir sobre uma cidadania democrática de liberdades, oportunidades e responsabilidades iguais para os indivíduos (MONTEIRO, 2002).

Numa passagem escrita por Lima Barreto em sua obra, Triste fim de Policarpo Quaresma, num momento de reflexão o personagem Ricardo percebe o quanto há de história nos locais por onde passava, assim expressou o autor: Olhou as casas, as igrejas, os palácios e lembrou-se das guerras, do sangue, das dores que tudo aquilo custara. $E$ era assim que se fazia a vida, a história e o heroísmo: com violência sobre os outros, com opressões e sofrimentos. É certo que cada lugar guarda em si momentos, expressões, memórias e significados, quer sejam individuais ou coletivos, demonstrando que a realidade é múltipla e diversa.

0 ensino de história deve então contribuir para a percepção dessa diversidade na realidade através de uma sólida formação cultural e humanística. Para esse fim o processo de ensino-aprendizagem precisa ser processado num ambiente de debates e de problematizações de contextos históricos que valorizem um olhar local, destacando as experiências individuais e/ou coletivas de forma a motivar uma compreensão de si enquanto agente do processo social, bem como, considerar a diversidade de realidades presentes em sala de aula para desenvolver ações estratégicas que contemplem diversidades culturais, religiosas, sociais e económicas. Conforme assinala Neves (2008),

A localidade se constitui no espaço onde uma comunidade se estabelece e se desenvolve. Configura, portanto, uma construção humana, empreendida em organizações comunitárias, com identidades internas e vinculações externas, de modo que extrapola as circunscrições projetadas por governantes, técnicos, estudiosos e incorpora fatores históricos de natureza social, econômica, política e cultural.

No recorte que prioriza o local, cada detalhe pode adquirir um significado próprio, o que não ocorre numa abordagem centrada em planos mais macroscópicos de análise. A análise local coloca em destaque a perspectiva da diversidade e a pluralidade das identidades, no entanto, é importante observar que uma realidade local não contém em si mesma os fundamentos de sua própria explicação.

Conforme assinalou Freire (1996), me movo como educador porque, primeiro me movo como gente, por isso ensinar exige compreender que a educação é uma forma de intervenção no mundo. Assim sendo, a prá- 
tica docente deve buscar um conhecimento emancipador e libertador para o exercício de uma cidadania plena em que o aluno possa ter acesso aos instrumentos cognitivos coerentes para questionar, analisar, desenvolver hipóteses e criticar a sua realidade.

Num mundo progressivamente globalizado e dominado pela economia dos serviços, na qual o turismo e a "animação cultural" desempenham papel fundamental, o que se vê, em grande medida, é a identidade histórica mitificada e "triturada" por avalanches de turistas (WINISK, 2012). Neste cenário é uma educação humanística considerar os interesses do aluno na construção e compreensão do conhecimento histórico, suas aproximações afetivas, cognitivas e suas vivências culturais.

A história local é uma forma de compreender a consciência histórica das experiências de vida partilhadas por determinados sujeitos. Crianças, jovens e adultos, sensibilizados por intermédio de uma reflexão sobre o local, unidade próxima e vizinha, historicizando e problematizando o sentido das suas identidades, relacionando-se com o mundo de forma crítica, mudando, ou não, enquanto sujeitos, a própria história, estão assim a desenvolver uma consciência histórica.

Cabe ao professor de história aliar a realidade histórica local com o contexto nacional ou internacional, com uma interrogação permanente sobre os sentidos inerentes ao local de maneira crítica e com a participação dos alunos de forma a desenvolver a percepção de que o conhecimento se produz na coletividade.

É válido lembrar as anotações de Koselleck (2006) quem busca encontrar o cotidiano do tempo histórico deve contemplar as rugas no rosto de um homem, ou então as cicatrizes nas quais se delineiam as marcas de um destino já vivido. Assim, a história local pode ser vista como "estratégia de ensino", para o desenvolvimento de atividades diretamente relacionadas com a vida quotidiana de forma que o aluno se entenda como integrante de uma comunidade, construa a sua própria historicidade e produza a identificação de si mesmo e também do seu redor, percebendo desta forma quanto há de História em sua vida que é construída por ele mesmo e quanto tem a ver com elementos externos a ele próprio (SCHMIDT, 2007).

É através do conhecimento histórico, da percepção das ações do homem num tempo que já não é presente que se estabelecem as relações entre as percepções dos sujeitos individuais e coletivos num lugar sendo que a materialização dessas percepções se processam no curso de uma experiência histórica através dos atos de nomear, identificar ou localizar os lugares onde se vive. Desta forma, expressou Neves (2008) que a história regional e local é um meio de se alcançar o conhecimento de viveres e saberes em dimensões inatingíveis por outras abordagens sistêmicas ou de abrangências espaciais mais amplas, como por exemplo, o quotidiano de pequenas comunidades, afinidades, comparações e interconexões locais, nacionais, continentais e universais, bem como as especificidades das comunidades.

0 trabalho com espaços menores pode facilitar o estabelecimento de continuidades e diferenças, evidências de mudanças, dos conflitos e das permanências. Uma história que otimiza as especificidades permite recuperar a vivência pessoal e coletiva dos alunos e vê-los como participantes da realidade histórica, a qual deve ser analisada e retrabalhada, com o objetivo de transformar em conhecimento histórico e em autoconhecimento. $\mathrm{O}$ aluno e o professor ao conhecerem aspectos específicos de sua localidade poderão compreender a historici- 
dade das coisas de uma maneira atraente e divertida explorando arquivos, patrimónios, a imprensa local e outros documentos.

O passado já foi, o presente já não é, e o futuro é uma esperança. Desse modo, a reflexão racional sobre a existência do homem atravessou tempos para dizer que existimos, para perguntar porque existimos e para inventar novas formas de existir unindo assim os saberes com as práticas.

\section{O QUOTIDIANO}

Um ensino de história humanizado também prioriza os fundamentos do conhecimento histórico, da cultura e da cidadania de forma qualitativa para o aluno. À vista disso, através de exercícios constantes e vivências de situações em que se sinta a produção objetiva do saber se estimulam elementos do quotidiano e a participação do aluno no processo de aprendizagem ao invés da simples assimilação de fatos, datas, dados, personagens, acontecimentos em monótonas aulas teóricas, algumas brilhantes e na maioria maçantes. Monteiro (2018) explica que, ao se centrar as atividades letivas nos alunos, não significa que os professores assumam um papel menos importante, por isso, a experiência de um educador em história precisa enfatizar a necessidade de uma reflexão sobre a prática pedagógica.

0 professor de história deve procurar o enriquecimento de sua base teórica e metodológica para orientar um processo de ensino-aprendizagem significativo. Também cabe observar que, ao desenvolver a prática pedagógica, esse professor precisa considerar a existência de pré-requisitos e o domínio dos conceitos básicos, como bem explicitou Fenelon (1986) não se pode perder de vista o desenvolvimento de uma consciência crítica do aluno diante da realidade a partir de um ponto científico.
Equivale anotar que é importante que os alunos se familiarizem com a metodologia do trabalho científico aplicada à História, aprendendo não só a estudar, como também os processos adequados à pesquisa, ao tratamento de dados e à análise de documentos (MONTEIRO, 2018). Nesse sentido, o conteúdo não pode ser dado como algo pronto, acabado e inflexível. Pelo contrário, deve ser organizado criticamente pelo aluno, sob a orientação do professor.

Portanto, torna-se fundamental que aconteçam atividades que tornem possível o desenvolvimento da criatividade e do raciocínio reflexivo e crítico que vão instrumentalizar o aluno para a compreensão do seu contexto histórico, cultural e social tornando-o apto para agir positivamente em sua transformação. Um ensino eficaz, atraente e abrangente é capaz de instrumentalizar o aluno para a compreensão das profundas transformações recentes, sem esquecer que o mundo atual é o resultado de um longo e contraditório processo histórico. Parafraseando Marc Bloch (2001), a história não pode ser reduzida a leis ou estruturas, uma história problema com seus sucessos e reveses é raramente tediosa.

Conforme assinala Fonseca (2007) na escola há um complexo processo no qual os saberes históricos e pedagógicos, os valores culturais e políticos são transmitidos e reconstruídos pelos sujeitos históricos que trazem consigo um conjunto de crenças, significados, valores, atitudes e comportamentos adquiridos em variadas experiências. E, por isso, é importante se considerar no ensino e na aprendizagem, variadas fontes de saber e de recursos, tais como o cinema, a televisão, a banda desenhada, a literatura, a imprensa, as múltiplas vozes dos cidadãos e os acontecimentos quotidianos. 
A utilização de comentários de documentos que tenham sintonia com os conteúdos enfocados é uma estratégia essencial no ensino de história, pois assim o aluno pode observar, analisar, comparar, criticar, induzir verdades, exercitar o seu sentido de objetividade e de imparcialidade, desenvolvendo tanto o respeito pelos factos, quanto a dúvida científica (MONTEIRO, 2018).

É assim que ao diversificar as fontes e ao dinamizar as práticas, amplia-se o acesso ao saber, possibilitando o confronto e o debate de diferentes visões, estimulando a percepção da complexidade da cultura e da história na experiência humana. Contudo, deve-se ter em atenção que estas novas perspectivas e abordagens enriquecem o ensino de história, porém o professor precisa estar atento aos métodos de como analisar os pressupostos historiográficos contidos no material considerando os temas a serem abordados.

É possível mostrar filmes, adequados ao nível etário e cognitivo dos alunos, exibindo trechos principais e dialogar o conteúdo a partir da exibição completa ou não, como também apresentar poemas relacionando -os com o contexto histórico da produção. Por exemplo, O sentimento do mundo de Carlos Drummond de Andrade relaciona-se com a Segunda Guerra Mundial; E então o que quereis de Maiakovski refere-se à Revolução Russa. Outra opção é trabalhar a criticidade do aluno através da produção musical. Por exemplo, Podres poderes de Caetano Veloso pode ser utilizada enquanto abordagem sobre a sociedade e a realidade política do Brasil nos anos 60, Mestre sala dos mares de João Bosco para tratar do contexto do Brasil República, especificamente da Revolta da Chibata e Alexandre de Caetano Veloso para se refletir sobre a Grécia Antiga, mais especificamente o helenismo.
A harmonia entre os recursos coerentes, a adequação dos conteúdos e da abordagem ao nível etário e cognitivo dos alunos resultam no estímulo da autonomia do aluno enquanto alguém capaz de elaborar dúvidas e pesquisar respostas. Monteiro (2018) explica que as orientações do professor devem incidir na explicação sobre como utilizar corretamente as bibliografias ou como consultar os ficheiros, e a elaborar fichas de leitura para que o aluno, sozinho ou integrado num grupo de trabalho, se torne autónomo no trabalho a efetuar, pois, nenhum tipo de recurso substitui o professor.

Também o excesso de recursos pode atrapalhar a devida compreensão de conceitos essenciais à disciplina histórica. Sobre isso, avisa Karnal (2008) uma aula pode ser extremamente conservadora e ultrapassada contando com os mais modernos meios audiovisuais (...) é a própria concepção de história que deve ser repensada. Não se pode deixar de lado a formação e o conhecimento em troca de simplificadoras informações, assim confunde-se informação com educação. E sobre isso Pinsky (in: Karnal - org. 2008) alerta:

Procurando acompanhar "modismos" muitos professores acabam comprando a ideia de que tudo que não é veloz é chato. Na sala de aula o pensamento analítico é substituído por "achismos", os alunos trocam investigações bibliográficas por informações superficiais dos sites "de pesquisa" pasteurizados (...) o conteúdo da disciplina é deixado de lado em nome de abordagens simplificadas.

O "modus operandi" em muitas salas de aula hoje em dia é substituir os livros por pesquisas virtuais, debates sem conteúdos, levando a um progressivo empobrecimento cultural de alunos e professores. 0 pensamento crítico não se sustenta sem leitura e reflexão. $\mathrm{Na}$ "era da informação", os famosos sites de busca e a opção ctrl+c / ctrl+v (cor- 
ta e cola), é uma perigosa fragmentação do conhecimento, falsa autonomia de aprendizagem e superficialidade de abordagem.

A autenticidade da prática de ensinar e aprender, conforme expressou Paulo Freire (1996) é uma experiência política, ideológica, gnosiológica, pedagógica, estética e ética em que a postura adotada pelo docente deve dar mãos com a decência e com a seriedade em que a tarefa do docente não é apenas ensinar os conteúdos, mas ensinar a pensar criticamente. Assim, a educação não significa um mero conjunto de atos de transmissão de conhecimentos, mas sim a criação de oportunidades para a construção coletiva de saberes.

O professor é um mediador e aprende juntamente com o aluno. 0 professor coordena e orienta as atividades, criando condições para se efetivar a prática educativa estimulando nos estudantes a responsabilidade e consciência crítica. Por sua vez, Milton Santos (2012) considera o professor como intelectual que mais do que se fixar numa cátedra e ser reconhecido por sua produção teórica, representa e expressa o que é necessário à população. Desta forma, os intelectuais/professores deveriam trabalhar visando a transformação da ordem posta, em prol do movimento da história.

\section{A VERDADE}

Carlos Drummond de Andrade, poeta brasileiro, escreveu em versos a sua noção de verdade. Conta que tentaram encontrar a porta da verdade, mas, nas portas possíveis só passava meia pessoa de cada vez, então só se atingia sempre a meia verdade. Entretanto, os meios perfis de verdade não coincidiam, e perante o dilema, cada um optou conforme seu capricho, sua ilusão, sua miopia, numa clara conclusão de que não existe a verdade absoluta.
Para Popper (1972) o conhecimento é de natureza provisória. Em nenhum momento há condições para demonstrar que aquilo que sabemos é verdadeiro, e é sempre possível que o conhecimento adquirido se revele falso. Assim, nenhuma teoria poderia ser encarada como verdade final. Na concepção de Popper (1972), não é a posse do conhecimento, da verdade irrefutável, que faz o homem de ciência. 0 que o faz é a persistente e arrojada procura crítica da verdade. Conforme Magge (1974) uma das citações preferidas de Popper é retirada de Xenófanes:

Os deuses não revelaram, no inicio, todas as coisas para nós; com o correr do tempo, entretanto, pela pesquisa, podemos saber mais acerca das coisas. Contudo, a verdade certa, nenhum homem a conheceu, nem chegará a conhecer, nem os deuses, nem mesmo acerca das coisas que menciono. Pois ainda que, por acaso, viesse a dizer, a verdade final, ele próprio não o saberia: Pois tudo não passa de teia urdida de pressupostos.

Popper é uma grande expressão da aproximação entre as ciências naturais e as ciências humanas e sociais evidenciando o vasto campo da interdisciplinaridade e constatação dos limites da verdade científica. Como bem explicitou Weber (1993) devido à inevitável variação das ideias de valor básicas, não há conceitos históricos verdadeiramente definitivos, passiveis de serem considerados como um fim último geral.

Assim, o professor de História deve auxiliar a consciência dos alunos de que é preciso aprender a conviver com a dúvida e, sobretudo, ensinar a pensar historicamente e admitir que não existem garantias de condições ideais para realizar todas as possibilidades da própria crítica. Isto implica desconstruir polaridades interpretativas não se contentando com os sentidos modelares, explicações únicas, mas estar sempre dis- 
posto a buscar outros significados contidos nos materiais, nas fontes, explorando também, para além delas, a compreensão das questões levantadas. E sobretudo ser capaz de manter a capacidade crítica bem alerta para conseguir analisar os acontecimentos da conjuntura em curso.

Diz-se que a escola contemporânea está em crise. Ora, a crise da escola é também a crise de legitimidade da profissão docente, já que os professores não são mais a única autoridade em matéria de cultura, disputando o espaço com a televisão, os jornais, a publicidade, dentre outros. Em suma, os professores precisam quotidianamente provar sua utilidade. Mas, deixar-se levar pela crise sem procurar superá-la, seria fugir à responsabilidade que nos advém da própria consciência histórica de nossa capacidade de agir para transformar o processo vivido, quando nos dispomos a isso. É assim que as questões para o planeamento didático do ensino de história não se esgotam mais no "como" ensinar, e sim avançam sobre "o que", "por que" e "desde quando" ensinar (MONTEIRO, org. 2007).

Monteiro (2018) anotou que a escola está hoje numa encruzilhada, onde o passado se encontra com o futuro a ser construído no presente, gerando uma situação muito complexa e cheia de interrogações, tal como a seguinte inquietação explicitada,

Chamo escola armazém à escola onde os jovens se limitam a estar, enjoados das matérias que já ouviram por duas ou três vezes, com os olhos no vazio, as mãos nos bolsos dos blusões, a pastilha na boca, o boné na cabeça... sem uma caneta, sem um livro, sem uma simples folha, com uma atitude displicente $e$ desafiadora! Como aquele aluno que me disse durante uma visita a uma escola relacionada com a formação inicial de professores, que a escola dava habilitações a mais para quem estava destinado a fazer cimento...
Em contrapartida a escola humanizada possibilita um encontro com a cultura, permitindo a expressão crítica e a autonomia dos alunos num processo de socialização.

Desta forma, o professor de História precisa desenvolver no aluno a capacidade de opinião, de construir seu próprio discurso. Não crer na história, mas compreendê-la.

A compreensão faz parte de um processo de aprender a aprender que é aprender a desaprender e a aprender novamente. Numa de suas conferências Foucault (2000) explicitou bem essa capacidade de aprender a aprender quando expressou a consciência da falsidade de sua argumentação e solicitação de perguntas, de críticas, de objeções por parte do seu público, pois ao se afastar da rigidez científica é que realmente se faz o progresso do saber.

Portanto, algumas questões são fundamentais para se ter em pauta. A ciência é uma verdade? A quem se serve com o que se faz? É assim que se estabelecem campos disciplinares e de práticas materiais e cognitivas múltiplas e se percebe que toda a atividade científica é de interpretação e também de invenção e por sua vez, todo encerramento de um debate ou todo consenso é local por natureza (PESTRE, 1996).

Santos (2002) se refere a um conhecimento prudente para uma vida decente em que deve haver uma intrinseca relação entre pesquisa/ação na universidade, bem como partilhar a atividade criadora do mundo com o trabalho da natureza, além de reinventar o contrato social. É preciso uma educação que ao invés de validar um conhecimento regulador, valide um conhecimento emancipador, de resistência.

Bittar (2014) assinala que ser resistente, no sentido da ética foucaultiana é ser capaz de exercitar a sua autonomia ante a conjuntura que força a pasteurização e a 
homogeneização dos comportamentos para servir ideologias hegemónicas. É não deixar se deixar sujeitar aos diversos contextos em que é possível resistir às inflexões do poder que se mascara e se reveste das mais diversas faces possíveis.

Conforme elucidou Foucault (1999) a própria verdade tem uma história, os historiadores não têm que decidir quem dizia a verdade, qual postulado é mais científico, mas preocuparem-se com a razão pela qual se diz. A desconstrução de padrões, discursos e legitimidades faz parte do exercício de interrogar, sobretudo, com o fim de mostrar à sociedade as possíveis intenções políticas, filosóficas e económicas que estariam regendo os discursos.

Dias (1994) referenda que o conhecimento é relativo às transformações contínuas da realidade, o enfoque dos processos de gênese, estruturação e desenvolvimento da atividade científica, devem sempre ser referenciados nas relações históricas e sociais que lhes dão significado. Por sua vez, Bruno Latour (1989), expressou que explicando a ciência se explica a sociedade e o inverso: se admitirmos que a historicidade aumenta na proporção inversa dos dados intemporais, então a análise das controvérsias faz-nos passar de uma história de sábios para uma história das ciências. Marc Bloch (2002) anotou sobre "o oficio do historiador" que o conhecimento do passado diz respeito às inquietações do presente, portanto, novos tempos levam a novas historicidades.

Também é importante dizer que é inútil buscar outra verdade que substitua a ciência naquilo que somente ela pode fornecer. A ciência não é a verdade, mas sua concepção de verdade não pode ser substituída por outra qualquer. Será isso verdade? Numa discussão sobre a verdade, é claro que encerramos com a necessária dúvida. Conforme explicitou Weber (1993) é inútil esperar a ciência perfeita e objetiva nascer, pois haverá sempre a subjetividade humana na objetividade científica. Como assinalei em outra argumentação ${ }^{1}$, o conhecimento histórico tem um papel fundamental na construção da ciência, entre os quais mostrar os limites da verdade e produzir criticidade em meio a postulados considerados legítimos.

\section{CONSIDERAÇÕES FINAIS}

Uma escola humanizada ajuda ao aluno compreender a história enquanto "ciência" do tempo e da mudança, bem como, a percepção da abrangência, dos limites e das consequências da ação humana no decorrer do tempo, assim como, promove integração, respeito, produção de saber em toda a diversidade cultural, religiosa, social e económica possíveis.

A abordagem da história local contribui para a percepção da diversidade na realidade, destaca vivências individuais para compor experiências coletivas na constituição de uma consciência histórica.

Os recursos utilizados no ensino de história devem valorizar a compreensão do processo histórico, sendo largamente indicado o uso de documentos condizentes com o nível etário e cognitivo dos alunos, bem como, da abordagem do assunto. Ao diversificar os recursos o professor de História não pode perder de vista uma sólida base conceitual e teórica que consolidam sua prática.

O estímulo com a inclusão de elementos do quotidiano e a efetiva participação do aluno no processo de aprendizagem possibilita a ampla compreensão do processo histórico ao invés da superficial assimilação

1 LIMA, Ana Paula. História é ciência? Considerações sobre a lógica da pesquisa científica. Revista Ciência \& Desenvolvimento - Fainor, Vitória da Conquista, v.7, n.1, p.108-115, jan./jun. 2014. 
de fatos, datas, dados, personagens e acontecimentos. É desta forma que educação significa promoção de oportunidades para a construção coletiva de saberes e não apenas transmissão de informações. Além de que solidariedade e amor ao próximo, concepções antigas, mas que não saem da pauta do dia, precisam continuar a ser integradas em sala de aula.

O conhecimento científico é de natureza provisória, pela inevitável variação das ideias e dos valores, não existindo conceitos históricos verdadeiramente definitivos e imutáveis. Por isso, o professor de História precisar auxiliar o aluno tanto a criar como a conviver com a dúvida inerente à produção do conhecimento, compreendendo a história como um processo em movimento. É assim que ao invés de se legitimar um saber regulador se constrói um conhecimento emancipador através da interrogação e das desconstruções de padrões e criação de outras noções racionais de compreensão do mundo.

\section{REFERÊNCIAS}

BAUMAN, Zygmunt. A ética é possível num mundo de consumidores?. Rio de Janeiro, Zahar, 2011.

BITTAR, Eduardo. Curso de ética jurídica: ética geral e profissional. 11ed. rev. atual. e modificada. São Paulo: Sairava, 2014.

BLOCH, Marc. Apologia da História ou o ofício do historiador. Rio de Janeiro: Jorge Zahar, 2001.

BARRETO, Lima. Triste fim de Policarpo Quaresma. São Paulo, Ática, 1983.

BARBOSA, Vilma. Ensino de História local: redescobrindo sentidos. Revista História [15]; João Pessoa, jul. /dez. 2006.

DIAS, A. L. M. Uma crítica aos fundamentos do ensino autoritário e reprodutivo da matemática. 1994. 138 f. Dissertação (Mestrado em Educação) - Universidade Federal da Bahia, Faculdade de Educação, Bahia, 1994.
FENELON, Déa R. (org.). 50 textos de História do Brasil. São Paulo: Ed. Brasiliense, 1986.

FONSECA, Selva Guimarães. A constituição de saberes pedagógicos na formação inicial do professor para o ensino de história na educação básica. In: MONTEIRO, A.M.F.C.; GASPARELLO, A. M.; MAGALHÃES, M. S. (Orgs.). Ensino de história: sujeitos, saberes e práticas, Rio Janeiro: Mauad: Faperj, 2007.

FOUCAULT, Michel. A verdade e as formas jurídicas. Rio de Janeiro: Editora Nau, 2000.

FREIRE, Paulo. Pedagogia da Autonomia: saberes necessários à prática educativa. São Paulo: Paz e Terra, 1996.

KARNAL, Leandro. História na sala de aula: conceitos, práticas e propostas. 5. ed. São Paulo: Contexto, 2008.

KOSELLECK, R. Futuro passado: contribuição à semântica dos tempos históricos. Rio de Janeiro: PUC-Rio / Contraponto, 2006.

LATOUR, B. Pasteur e Pouchet: heterogénese da história das ciências, In: Para uma história das Ciências. [S.l.]: Terramar, 1989.

LIMA, Ana Paula. História é ciência? Considerações sobre a lógica da pesquisa científica. Revista Ciência \& Desenvolvimento - Fainor, Vitória da Conquista, v.7, n.1, p.108-115, jan./jun. 2014.

MAGEE, B. As idéias de Popper. São Paulo: Cultrix, 1974.

MONTEIRO, A.M.F.C.; GASPARELLO, A. M.; MAGALHÃES, M. S. (Orgs.).

Ensino de história: sujeitos, saberes e práticas, Rio Janeiro: Mauad: Faperj, 2007.

MONTEIRO, Miguel. "Da escola armazém à escola humanizada", in Actas do V Curso de Verão da Ericeira. 26, 27 e 28 de Junho de 2003. Ericeira, Mar de Letras, 2004, pp. 77-83.

. "O ensino numa escola plural". in Actas do IV Curso de Verão da Ericeira. 6, 7 e 8 de Junho de 2002. Ericeira, Mar de Letras, 2002, pp. 43-49.

"O Ensino da História" in O Ensino na Escola de Hoje - Teoria, Investigação e aplicação, cap. 8. Feliciano H. Veiga. (coord), Lisboa, 2017. 
NEVES, Erivaldo Fagundes. História regional e local: fragmentação e recomposição da história na crise da modernidade. Feira de Santana: UEFS; Salvador: Arcádia, 2002.

História e região: tópicos de história regional e local. Ponta de Lança, São Cristóvão v.1, n. 2, abr.-out. 2008.

PESTRE, Dominique. Por uma nova história social e cultural das ciências: novas definições, novos objetos, novas abordagens. Cadernos IG/ Unicamp, vol. 6, n.1, 1996, p 3-56.

POPPER, K. A lógica da pesquisa científica. São Paulo: Cultrix, 1972.

ROCHA, Aristeu Castilhos. Proposta metodológica para o ensino de História. Disponível em: http://www.sicoda.fw.uri.br/revistas/artigos/1_5_54.pdf. Acesso em dezembro de 2018. Revista de História Unicruz, 2002.

SANTOS, Boaventura. Reinventar a democracia. 2ed. Lisboa: Gradiva, 2002.
SANTOS, Milton. Por uma Geografia Nova: da crítica da Geografia a uma Geografia Crítica. 6ed. São Paulo: EDUSP, 2012.

SCHMIDT, M. A. O ensino de história local e os desafios da formação da consciência histórica. In: MONTEIRO, A.M.F.C.; GASPARELLO, A. M.; MAGALHÃES, M. S.

(Orgs.). Ensino de história: sujeitos, saberes e práticas, Rio Janeiro: Mauad: Faperj, 2007.

WEBER, M. Metodologia das ciências sociais. 2. ed. São Paulo, Cortez - Campinas, Edunicamp, 1993.

WINISK, Guilherme. Dentro do nevoeiro: diálogos cruzados entre arte e arquitetura contemporânea. Tese de doutoramento. Programa de Pós-graduação da Faculdade de Arquitetura e Urbanismo da Universidade de São Paulo. São Paulo, 2012.
Recebido em: 19/04/2019

Aprovado em: 20/05/2019 